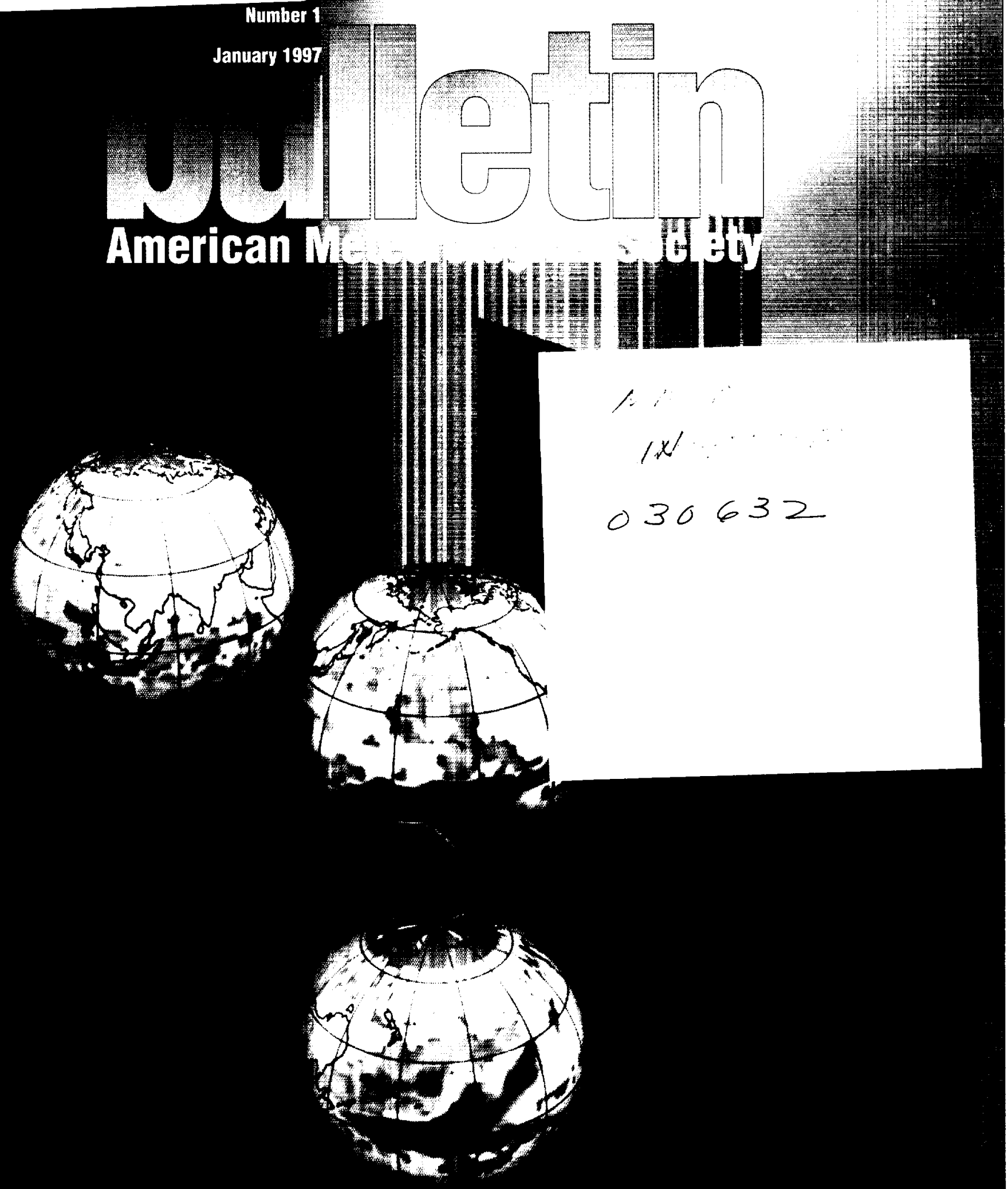




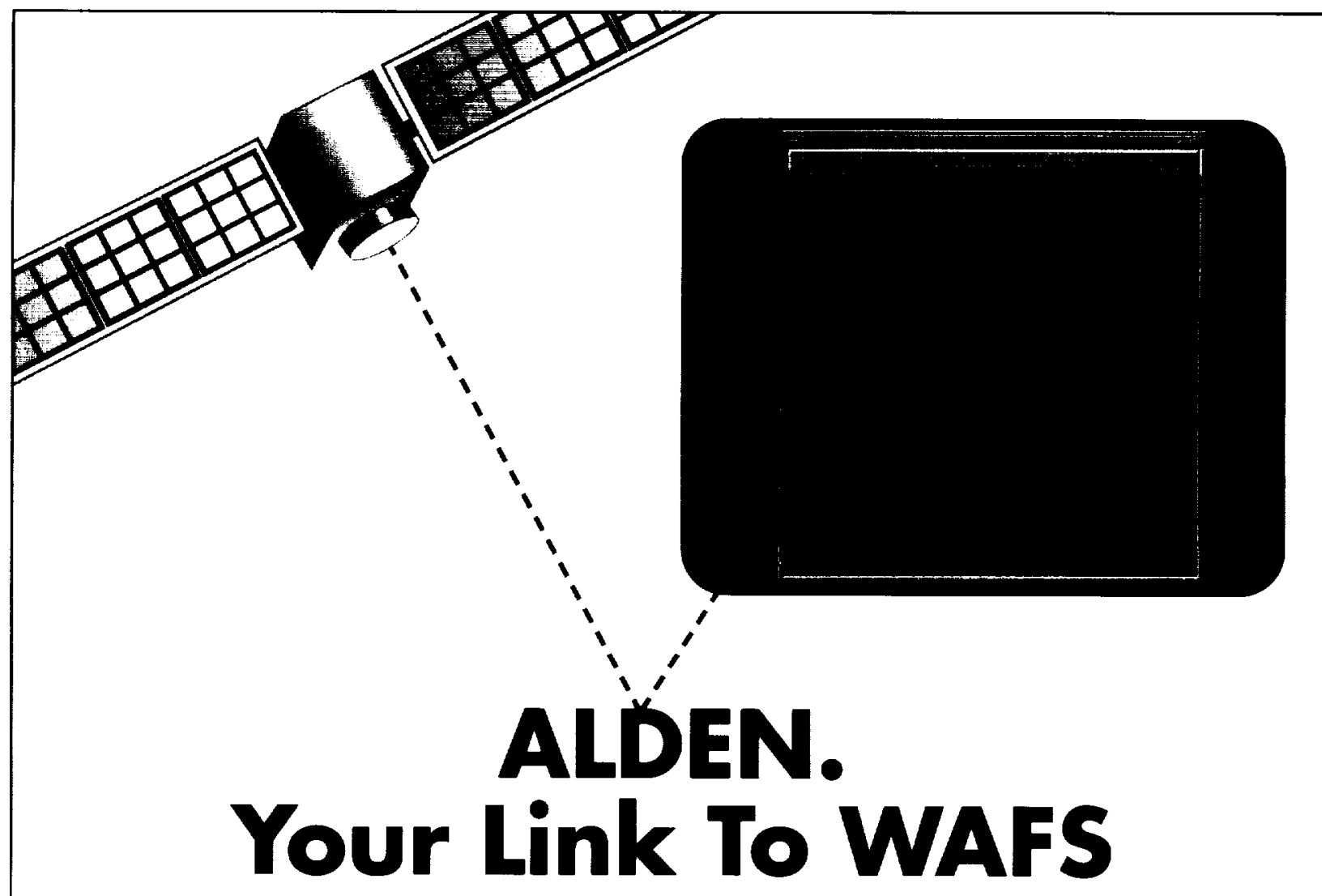

\section{Access WAFS With Alden Technology}

The World Area Forecast System (WAFS ), sponsored by ICAO, is a satellite communications system designed to provide the aviation community with essential meteorological information. WAFS products include Gridded global wind and temperature data in GRIB format, selected Significant Weather (SIGWX) charts in T4 facsimile code and Text data (OPMET). Alden's WAFS terminal provides easy to use display and analysis tools that:

- Display and manipulate data from individual station observations and forecasts

- Display groupings based on station names, ICAO identifiers, time, product type and geographical area

- Plot data in a vertical cross-section of the flight profile

- Display upper-air observations as a SkewT/Log-P

- Transmit weather charts and messages to remote pilot briefing terminals via modem or local area network

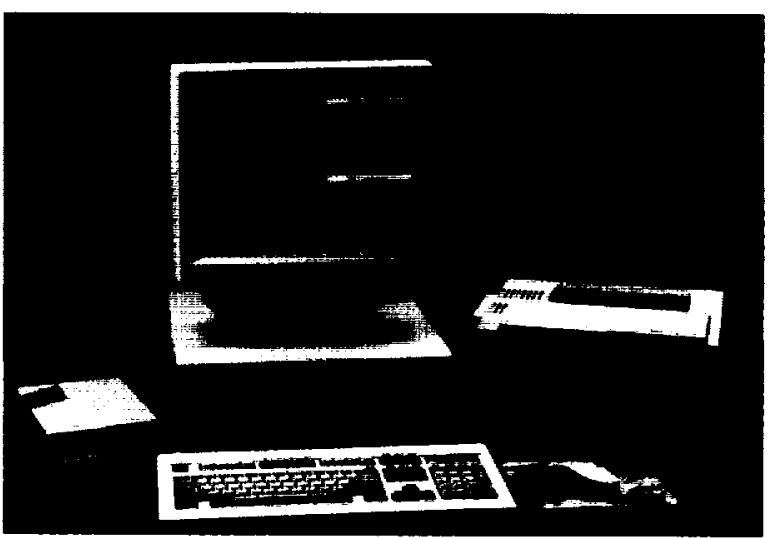

Alden's WAFS terminal was selected by the U.S. government to meet the needs of up to 32 countries. Alden has nearly five decades of experience providing weather display systems with proven reliability, backed by worldwide support.

To Link up with WAFS, Link up with Alden. Call 508-366-8851

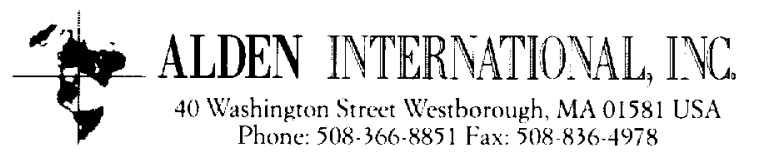




\title{
The Global Precipitation Climatology Project (GPCP) Combined Precipitation Dataset
}

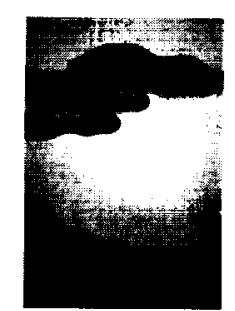

\author{
George J. Huffman,* Robert F. Adler,+ Philip Arkin," Alfred Chang, ${ }^{@}$ Ralph Ferraro, ${ }^{\star}$ \\ Arnold Gruber, ${ }^{\&}$ John Janowiak, ${ }^{*}$ Alan McNab, ${ }^{* *}$ Bruno Rudolf, $^{++}$and Udo Schneider ${ }^{++}$
}

\begin{abstract}
The Global Precipitation Climatology Project (GPCP) has released the GPCP Version 1 Combined Precipitation Data Set, a global, monthly precipitation dataset covering the period July 1987 through December 1995 . The primary product in the dataset is a merged analysis incorporating precipitation estimates from low-orbit-satellite microwave data, geosynchronous-orbit-satellite infrared data, and rain gauge observations. The dataset also contains the individual input fields, a combination of the microwave and infrared satellite estimates, and error estimates for each field. The data are provided on $2.5^{\circ} \times 2.5^{\circ}$ latitude-longitude global grids. Preliminary analyses show general agreement with prior studies of global precipitation and extends prior studies of El Niño-Southern Oscillation precipitation patterns. At the regional scale there are systematic differences with standard climatologies.
\end{abstract}

\section{Introduction}

The latent heating associated with precipitation is a primary atmospheric energy source; the spatial and temporal distribution of precipitation around the globe is crucial information for advancing our ability to model and predict global long-range weather and climate changes. Furthermore, as reviewed by Arkin and Xie (1994), the distribution of precipitation is needed

*NASA/GSFC Laboratory for Atmospheres, and Science Systems and Applications, Inc., Greenbelt, Maryland.

+NASAVGSFC Laboratory for Atmospheres, Greenbelt, Maryland. NOAA/NWS National Centers for Environmental Prediction. Camp Springs, Maryland.

NASA/GSFC Laboratory for Hydrospheric Processes, Greenbelt, Maryland.

\&NOAA/NESDIS Office of Research and Applications, Camp Springs, Maryland.

**NOAA/NESDIS National Climatic Data Center, Asheville, North Carolina.

+'Deutscher Wetterdienst, Global Precipitation Climatology Centre, Offenbach am Main, Germany.

Corresponding author address: George J. Huffman, Code 912 , NASA/GSFC, Greenbelt, MD 20771.

E-mail: huffman@agnes.gsfc.nasa.gov

In final form 31 July 1996.

C1997 American Meteorological Society for a variety of other scientific uses, such as climate diagnostic studies, and societal applications such as water management for agriculture and power, drought relief, flood control, and flood forecasting. The task of quantifying the distribution is complicated by the fact that no single currently available estimate of precipitation has the necessary coverage and accuracy over the whole globe.

The Global Precipitation Climatology Project (GPCP) was established by the World Climate Research Program (WCRP) in 1986 to address this problem [WCRP (1986); see Arkin and Xie (1994) for a summary of its initial objectives and organization]. The GPCP's present goal is to provide monthly mean precipitation data on a global $2.5^{\circ} \times 2.5^{\circ}$ latitudelongitude (lat-long) grid for the period 1986-2000. The general approach is to combine the precipitation information available from each source into a final merged product, taking advantage of the strengths of each data type. The microwave estimates are based on Special Sensor Microwave/Imager (SSM/) data from the Defense Meteorological Satellite Program (DMSP, United States) satellites that fly in sun-synchronous low-earth orbits. The infrared (IR) precipitation estimates are obtained primarily from geostationary satellites operated by the United States, Europe, and Japan, and secondarily from polar-orbiting satellites. 
The gauge data are assembled and analyzed by the Global Precipitation Climatology Centre (GPCC) of the Deutscher Wetterdienst.

The individual single-source estimates (microwave, IR, gauge data) are valuable in their own right and have been used in a variety of scientific studies (e.g., Janowiak and Arkin 1991; Chang et al. 1995; Weng et al. 1994; Rudolf et al. 1996). Each input dataset has strengths and weaknesses in estimating global precipitation. The precipitation estimates made from geostationary IR data are based on frequent $(3 \mathrm{~h})$ images, thereby providing good temporal resolution of precipitation systems and coverage of the diurnal cycle. However, the relation between IR radiance and instantaneous surface precipitation is relatively weak and useful primarily for deep convective systems in the zone $40^{\circ} \mathrm{N}-\mathrm{S}$. The SSM/I radiances have a strong connection with surface rainfall, especially over the ocean, and are useful to much higher latitudes. However, the SSM/I observations have poor temporal sampling, averaging only 1.2 images day $^{-1}$ in the Tropics and subtropics with one satellite. Gauge reports are considered very accurate (at least after correction for systematic measurement errors), but gauge sites are mostly limited to land areas and are concentrated in developed countries.

Recognizing such shortcomings, the GPCP has promoted the development of an analysis procedure for blending the various estimates together to produce the necessary global gridded precipitation field. The current procedure is based on Huffman et al. (1995) and has been used to produce the GPCP Version 1 Combined Precipitation Data Set, covering the period July 1987 through 1995 . The primary product in the Version 1 dataset is a combined observation-only dataset, that is, a gridded analysis based on gauge measurements and satellite estimates of rainfall. It will be useful for climate model validation, hydrological and climate monitoring, and diagnostic studies. Gaps in coverage at high latitudes will be addressed in a future release that may include numerical weather prediction or additional satellite estimates of precipitation.

The following sections describe the techniques used in the GPCP Version 1 dataset and provide examples. Section 2 summarizes the input datasets and the approach used to arrive at the error estimates for those fields. Section 3 describes the technique used to combine the individual estimates into the blended products. Examples of the products, some preliminary research results, and initial validation studies are pre- sented in sections 4 and 5. A summary and directions on how to obtain the dataset are given in section 6 .

\section{Individual dataset summaries}

\section{a. Rain gauge analysis}

Precipitation measurements from rain gauges generally have high accuracy. However, they represent point values of a highly variable parameter observed on a sparse irregular grid and must be converted to area means before use in most applications. The GPCC uses a variant of the SPHEREMAP interpolation routine (Willmott et al. 1985) to interpolate the station data to regular grid points $\left(0.5^{\circ}\right.$ lat-long mesh). These regular points are then averaged to provide area-mean monthly total precipitation on $2.5^{\circ}$ grid cells. A detailed description of the GPCC data processing and analysis system is given by Rudolf (1993).

Quality control is crucial before carrying out the analysis because some records are contaminated by coding, typing, or transmission errors. The GPCC manually reviews station location and has developed a two-step quality control for precipitation records. The first automatic check on precipitation compares individual data values to area means and climatological normals. Questionable data are reviewed in the second manual step, which considers orographic conditions and catalogs of catastrophic events. The second step is key to capturing the extreme events that characterize the time-space distribution of precipitation (Rudolf 1993; Schneider 1993).

Precipitation measurements from rain gauges are also affected by systematic errors, that is, losses due to wetting, evaporation, or aerodynamic effects. The last is more important for snow than for rain. The GPCC uses the climatological estimates of systematic error from Legates (1987), which are based on Sevruk's (1989) approach.

The Version I rain gauge product is based on about 6700 rain gauge stations worldwide, mostly synoptic and monthly climate reports collected from the Global Telecommunications Network in real time, supplemented by other worldwide or continental data collections. Currently the GPCC is working to assemble and quality control a much larger set of stations (about 40000 ).

\section{b. Microwave estimates}

The microwave brightness temperatures $\left(T_{b}\right)$ observed from a spaceborne sensor are dependent 
upon the emission from the earth's surface and modified by the intervening atmosphere, principally due to hydrometeors. Since mid-1987 the SSM/I has been the main source of microwave data, providing four frequencies $(19.35,22.235,37$, and $85.5 \mathrm{GHz})$ with dual polarization on each frequency (except vertical alone at $22 \mathrm{GHz}$ ). The GPCP has chosen to employ two SSM/I algorithms, one for ocean regions based on emission and the other for land areas based on scattering.

\section{1) EMISSION ESTIMATE}

Water surfaces have low emissivity, so the emission signal in the lowest-frequency SSM/I channels due to hydrometeors is clearly detectable over oceans. In particular, the $T_{b}$ for the vertically polarized $19.35-\mathrm{GHz}$ channel $\left[\mathrm{T}_{b}(19 \mathrm{v})\right]$ can be related to the rain intensity over the dynamic range of $2-25 \mathrm{~mm} \mathrm{~h}^{-1}$ from first principles with only a few approximations. Following the Wilheit et al. (1991) histogram approach to retrieving rainfall, the rain rate is modeled as a mixed distribution made up of a discrete probability of no rain and a lognormal distribution for rain events. Hence, the parameters of the rain-rate probability distribution function can be related to the lower-frequency SSM/I $T_{b}$ histogram for the month and solved iteratively. The SSM/I channel combination $\left[2 T_{b}(19 v)-T_{b}(22 v)\right]$ is used to minimize the effect of varying water vapor in the atmospheric path. The height of the freezing level, which is needed by the radiative transfer calculation, is determined from scattergrams of $T_{b}(19 v)$ and $T_{b}(22 v)$. The resulting $\mathrm{SSM} / \mathrm{I}$ rain-rate estimates are multiplied by 1.5 to account for the beam-filling bias (Wilheit et al. 1991; Chiu et al. 1993). Whenever the method fails to converge on the nominal $2.5^{\circ}$ lat $\times 2.5^{\circ}$ long grid, values computed on a $5^{\circ}$ lat $\times 5^{\circ}$ long grid are substituted. The emission estimates are computed by the Laboratory for Hydrospheric Processes at the NASA/Goddard Space Flight Center.

\section{2) SCATtERING ESTIMATE}

Ice hydrometeors scatter upwelling radiant energy at the higher SSM/I frequencies, an effect that provides strong correlation with surface rainfall and is detectable over both land and water. The primary GPCP scattering algorithm is an $85-\mathrm{GHz}$ technique (Ferraro et al. 1994) based on the Grody (1991) scattering index (SI). It has separate components for land and ocean, as well as screening tests for the removal of artifacts caused by various surface types. The coastline is thickened by $50 \mathrm{~km}$, and the land component is applied over both land and "coast." The algorithm has been calibrated to instantaneous rain rates from ground-based radar measurements (Ferraro and Marks 1995).

A fall-back scattering technique was also required because the $85-\mathrm{GHz}$ sensors in the first operational SSM/I (aboard the DMSP F- 8 spacecraft) failed by June 1990 due to improper shielding from solar radiation. This failure prevented further use of the $85-\mathrm{GHz}$ SI until the advent of new SSM/I units aboard the DMSP F-10 and $F-11$ spacecraft in late 1991. In the interim, an alternate SI was employed that uses the scattering signal in $\mathrm{T}_{\mathrm{b}}(37 \mathrm{v})$. The $37-\mathrm{GHz}$ SI was developed in parallel with the Grody (1991) study and includes a linear calibration with radar data. While the $85-\mathrm{GHz}$ SI technique can detect rain rates as low as $1 \mathrm{~mm} \mathrm{~h}^{-1}$, the $37-\mathrm{GHz}$ SI is only sensitive to rain rates of $5 \mathrm{~mm} \mathrm{~h}^{-1}$ or greater.

The monthly scattering-based rainfall field is computed by the Office of Research and Application of the NOAA National Environmental Satellite Data and Information Service as follows. SSM/I pixels are accumulated on separate daily $0.333^{\circ}$ lat-long grids for ascending and descending orbit segments. Then all these grids are averaged to a $2.5^{\circ}$ lat-long grid for the month.

For completeness, we note that the scattering estimates over ocean depend on additional processing (Weng and Grody 1994). As such, this additional processing solely affects the global scattering estimates that appear as the "SSM/I scattering" product in the Version 1 dataset, but not any of the other input or combination fields.

\section{3) Microwave Merger}

For the most part, the merger of the two microwave estimates is simply a case of taking histogram-based emission estimates over water and SI-based scattering estimates over land. However, the emission technique eliminates land-contaminated pixels individually, so near-coast emission estimates for the month can be the result of relatively few pixels. Some preliminary study led us to take the emission estimate alone when it has at least $75 \%$ of the sampling of the scattering technique, and at lower sampling values do a weighted interpolation between the two as

$$
R_{\text {combined }}=\frac{N_{\text {emiss }} R_{\text {emiss }}+\left(N_{\text {scat }}-N_{\text {emiss }}\right) R_{\text {scal }}}{N_{\text {scat }}},
$$


where $R$ is the precipitation rate and $N$ is the number of samples, and "combined," "emiss," and "scat" denote combined, emission, and scattering estimates, respectively. The somewhat low threshold of $75 \%$ was chosen because the two techniques count samples differently.

\section{c. IR estimate}

Each cooperating geostationary satellite operator (the Geostationary Operational Environmental Satellites, or GOES, United States; the Geostationary Meteorological Satellite, or GMS, Japan; and the Meteorological Satellite, or Meteosat, European Community) accumulates 3-h geo-IR imagery into 16-class histograms of IR $T_{b}$ on a $2.5^{\circ}$ lat-long grid in the zone $40^{\circ} \mathrm{N}-\mathrm{S}$ for each pentad of days (1-5 January, 610 January, ..., 27-31 December). Separate histograms are accumulated for each 3 -h period of the day $(0000,0300, \ldots, 2100$ UTC $)$, which preserves the mean diurnal cycle for each pentad. The global IR rainfall estimates are then generated from a merger of these data at the Climate Prediction Center using the GOES precipitation index (GPI; Arkin and Meisner 1987) technique, which relates cold cloudtop area to rain rate.

The original geo-IR data contain viewing-geometry effects, which impact the GPI estimates. The geometrical effects result in increased apparent cloud cover, correspondingly lower brightness temperatures, and erroneously high rainfall rates in regions that are far from the satellite nadir point. Empirical corrections have been developed for this effect (R. Joyce and P. Arkin 1997, submitted to J. Atmos. Oceanic Technol.) and applied to the GPI estimates used here. The GPI was not corrected in this study for the less-severe effects of intersatellite calibration, although R. Joyce and P. Arkin (1997, submitted to J. Atmos. Oceanic Technol.) have recently developed such corrections.

In cases where geostationary data are unavailable, the National Oceanic and Atmospheric Administration (NOAA) polar-orbiting satellites are used to provide three-class histograms of brightness temperature (Janowiak and Arkin 1991) or, when histograms are not available, just the integrated value of outgoing longwave radiation. GPI is derived from the histograms, and an estimate calibrated by GPI is generated by linear regression from the flux values (Janowiak and Arkin 1991). Depending on the satellites contributing, the NOAA data provide $0-4 \mathrm{im}-$ ages per day, at most half the samples available from the geostationary data.

\section{d. Error estimates}

It is critical to our understanding of the data, as well as to the combination approach described below, to have estimates of errors that vary with space and time for each precipitation field. Unfortunately, a general statement of the problem (see North et al. 1991) makes it clear that we will have to accept some strong approximations to achieve useful results with the techniques and data available.

The first step is to neglect bias error and only compute random errors. This approximation is justified because experience shows that random errors usually dominate bias for monthly $2.5^{\circ}$ grids. In addition, the combination technique adjusts biases in individual fields before combination, where possible. The second step is to develop functional representations of random error. This task is difficult because the various input data sources have such disparate behavior in any statistical properties beyond precipitation total. The final form for this study, described by G. Huffman (1997, submitted to J. Appl. Meteor.), is

$$
\sigma^{2} \cong \frac{\mathrm{H}(\bar{r}+\mathrm{S})}{N_{\mathrm{i}}}[24+49 \sqrt{\bar{r}}]
$$

where $\sigma^{2}$ is the error variance of an average over a finite set of observations, $\mathrm{H}$ is taken as constant (actually slightly dependent on the shape of the precipitation rate histogram), $\bar{r}$ is the average precipitation rate (in mm day ${ }^{-1}$ ), $\mathrm{S}$ is taken as constant (actually $\sigma$ for $\bar{r}=0$ ), $N_{\mathrm{i}}$ is the number of "independent" samples in the set of observations, and the expression in square brackets is a parameterization of the conditional precipitation rate based on work with the Goddard Scattering Algorithm, Version 2 (Adler et al. 1994) and fitting of (2) to the Surface Reference Data Center (SRDC) analyses described below. The third step is to set the "constants" $\mathrm{H}$ and $\mathrm{S}$ from data for each of the input single-source datasets by comparison against the SRDC and GPCC analyses and tropical Pacific atoll gauge data (Morrissey and Green 1991). Due to the form of (2), the computed value of $\mathrm{H}$ actually accounts for multiplicative errors in $N_{\mathrm{i}}$ and the conditional rain rate approximation (the term in square brackets) in addition to $\mathrm{H}$. It is important to use algorithm-determined precipitation to set the constants because the random error for a particular technique should reflect sampling both of the true rain field and of algorithm-dependent fluctuations about the true field. 
Early work on the error problem revealed that it was hard to use the absolute error estimates to study fluctuations in data quality, due to absolute error's strong dependence on rain rate. According to (2), $\sigma$ varies as $\bar{r}^{0.5}$ at low $\bar{r}$ and as $\bar{r}^{0.75}$ at high values. Relative error has a similar flaw, behaving as $\bar{r}^{-0.5}$ and $\bar{r}^{-0.25}$ at low and high $\bar{r}$, respectively. Consequently, for display purposes we defined an additional variable, quality index (QI), in which (2) was inverted to give $N_{\mathrm{i}}$ as a function of error, and $\mathrm{H}$ and $\mathrm{S}$ were set to the values estimated for gauges. The units of $\mathrm{QI}$ are "equivalent gauges," the approximate number of gauges required to produce the error in question (for the given rain total). Qualitatively, QI values near zero are poor and those over 10 are good.

\section{Combination method summary}

The GPCP combination method is designed to use the strengths of each input dataset objectively to produce merged global monthly precipitation fields that are superior to any of the individual datasets. The merger technique is an enhancement of the satellitegauge-model (SGM) technique described in Huffman et al. (1995). The technique is outlined in Fig. 1. The resulting suite of precipitation products allows users with different requirements to choose different products. Each precipitation product has an associated error estimate that makes it possible for users to assess the utility of the estimates.

As shown in Fig. 1 the microwave estimates are approximately time- and space-matched with geo-IR observations to derive a microwave/IR calibration ratio for each grid box (Adler et al. 1993). In the present case the "matched" GPI is found by computing the GPI from a month of 3-h geo-IR data that are closest in time to the nominal SSM/I overpass time. The ratio is controlled to prevent unstable answers, and it is smoothly filled in regions where the SSM/I is missing but the geo-IR is available. Alternately, in regions of light preciptation an additive adjustment is computed that is the difference between smoothed $\mathrm{SSM} / \mathrm{I}$ and GPI values when the SSM/I is greater, and zero otherwise. In regions lacking geo-IR data, such as the Indian Ocean sector, the low-orbit IR contained in the GPCP merged IR dataset is adjusted using a smoothly varying interpolation of the microwave/geoIR adjustment ratio. The spatially varying arrays of adjustment coefficients are then applied to the full set of GPI estimates, producing the adjusted GPI (AGPI) precipitation field, which has the sampling of the geosynchronous data and the bias of the instantaneous microwave estimates. Verification against rain gauge analyses over water and land and subjective examination of the resulting maps and zonally averaged fields indicate that known biases in the GPI in the subtropics and over land are reduced using this adjustment approach and that the AGPI estimates are superior to either the microwave or the GPI estimates alone (Adler et al. 1993, 1994).

The multisatellite (MS) estimate is formed from the three satellite sources (see Fig. 1): AGPI estimates where available $\left(40^{\circ} \mathrm{N}-\mathrm{S}\right)$, the weighted combination of the microwave estimate and the microwave-adjusted low-orbit IR elsewhere in the $40^{\circ} \mathrm{N}-\mathrm{S}$ belt, and the mi-

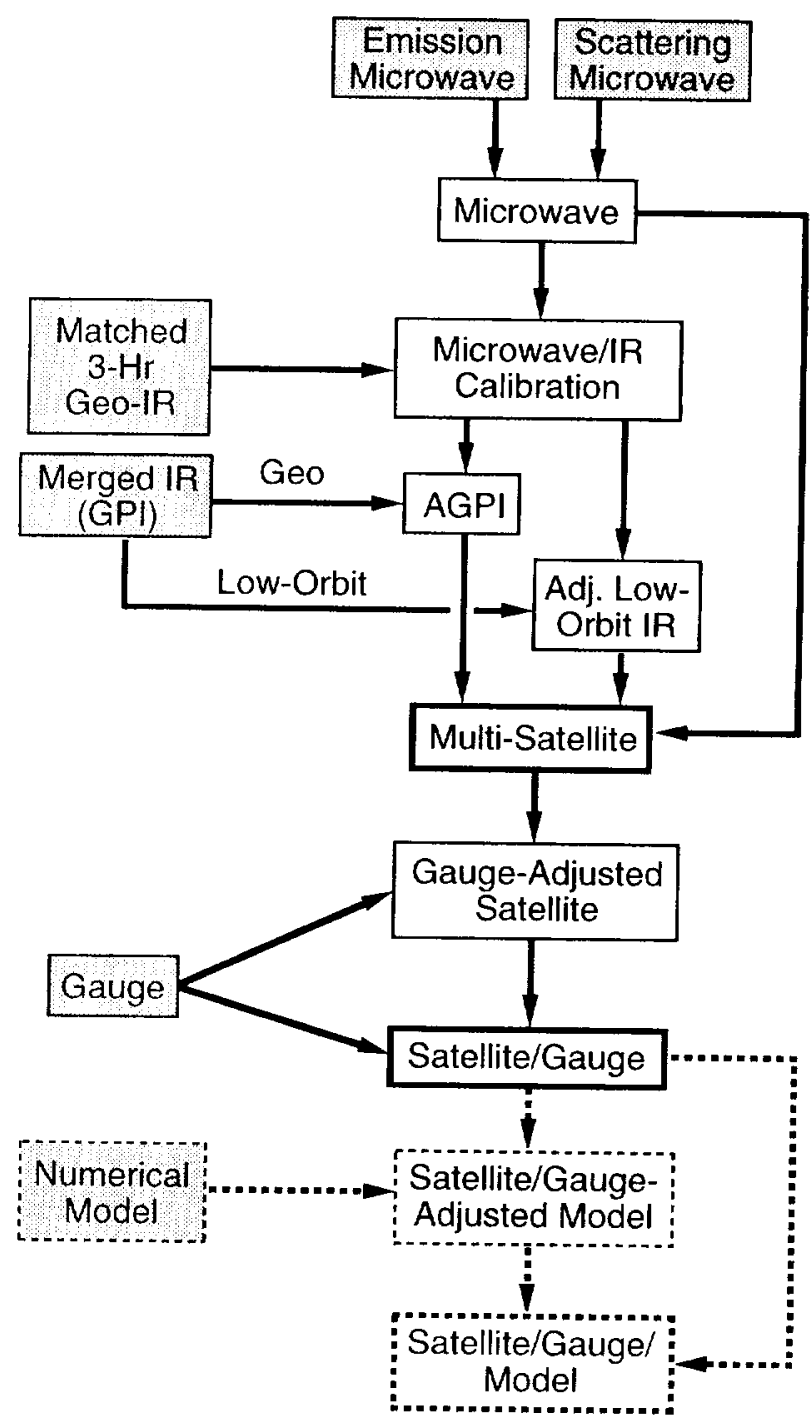

FIG. 1. Flow chart of satellite-gauge-model precipitation combination technique. 
crowave outside of $40^{\circ} \mathrm{N}-\mathrm{S}$. The combination weights are the inverse error variances of the respective estimates. Such weighted combination of microwave and microwave-adjusted low-orbit IR is done because the low-orbit IR does not have sufficient sampling to warrant the adjustment scheme used for the geo-IR.

The satellite/gauge (SG) estimate is computed in two steps (see Fig. 1). First, for each grid box over land the multisatellite estimate is muliplied by the ratio of the large-scale ( 5 grid boxes $\times 5$ grid boxes) average gauge analysis to the large-scale average of the multisatellite estimate. Alternatively, in lowprecipitation areas the difference in the large-scale averages is added to the multisatellite value when the averaged gauge exceeds the averaged multisatellite. This keeps the bias of the SG close to the (presumably small) bias for the gauge analysis on a regional scale, even while allowing the multisatellite estimate
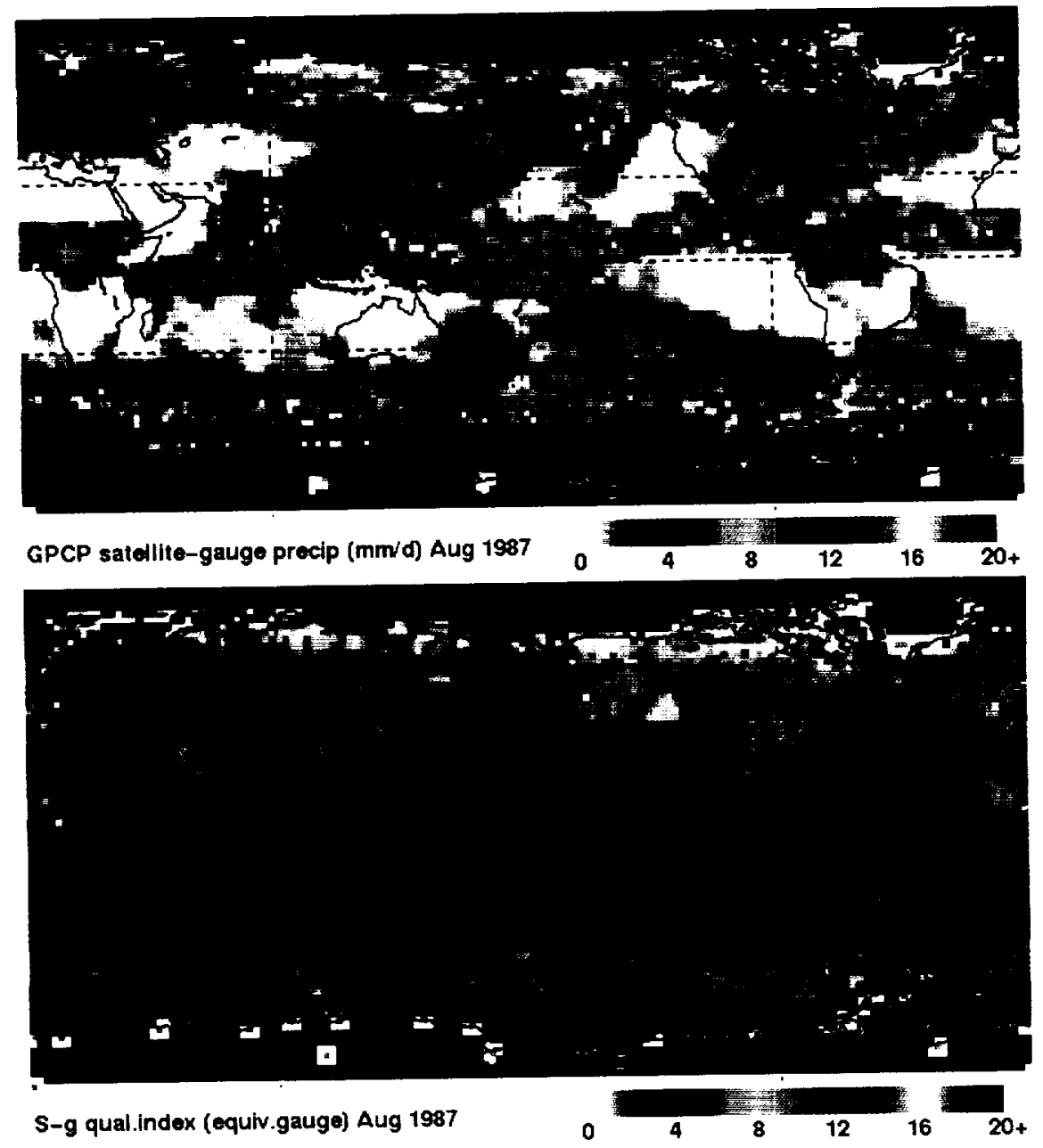

FIG. 2. Satellite-gauge (SG) estimate of precipitation (top, in $\mathrm{mm} \mathrm{day}^{-1}$ ) and quality index (bottom. in equivalent gauges) for August 1987. Blacked-out areas denote regions with no estimate. to provide important local detail. Second, the gaugeadjusted multisatellite estimate and the gauge analysis are combined with inverse-error-variance weighting.

Figure 2 provides an example of the GPCP SG estimate. Over oceans in the latitude belt $40^{\circ} \mathrm{N}-\mathrm{S}$ (except over the Indian Ocean) the estimate is principally based on the AGPI and shows its characteristic smoothness. Other oceanic regions are noisier, reflecting the lower sampling in the SSM/I. The land patterns have varying contributions by the gauge analysis, depending on location. Changes in data source are reflected as sudden changes in QI (bottom panel in Fig. 2). The blacked-out regions are considered to lack usable estimates from any of the sources. This quality control decision is objective and is based on factors such as the absence of SSM/I data (at very high latitudes), "high" coverage by ice and snow in the $\mathrm{SSM} / \mathrm{I}$ estimate, and a total absence of gauge reports. Note the relative lack of seams in the precipitation field between regions with different data coverages. The MS fields (not shown) appear very similar to the SG fields, partly because many oceanic areas have no gauges, and partly because the gauge and MS precipitation values are frequently similar. Closer inspection reveals quantitative differences, for example, higher values in the SG across northern Europe, and the SG quality index clearly shows higher confidence in many land areas.

\section{Results}

We now examine the validity and utility of the SG product through descriptive analyses (section 4) and quantitative comparisons (section 5). In this section we describe the spatial and temporal variability in the SG, compare them to long-term means published by Jaeger (1976, hereafter $J$ ) and Legates and Willmott (1990, hereafter LW) 
and compare the interannual variability in precipitation associated with the El Niño-Southern Oscillation (ENSO) during the 8.5-yr period with that described in studies based on historical gauge observations.

\section{a. Eight-year mean}

The top panel in Fig. 3 shows the SG precipitation averaged over the years 1988-95, while the middle and bottom panels of the figure contain the $\mathrm{J}$ and $\mathrm{LW}$ climatologies for comparison. The SG shows the expected main features, with maxima in the Tropics in the intertropical convergence zone (ITCZ) in the Atlantic, Pacific, and Indian Oceans; in the South Pacific convergence zone (SPCZ); and over tropical Africa and South America. Dry zones in the eastern parts of the subtropical oceans are evident. In the midlatitudes, the storm tracks in the Northern Hemisphere oceans are very distinct. In the Southern Hemisphere the circumpolar storm track is weaker with maxima southeast of Africa and South America and a poleward extension of the SPCZ in the South Pacific Ocean. Dry areas over North Africa, western North America, and Australia are well defined.

The general distribution of precipitation in the SG is similar to the two climatologies, but with significant differences in detail. We should expect this, given different analysis techniques and resolutions $\left(5^{\circ}\right.$ and $0.5^{\circ}$ lat-long grids for $\mathrm{J}$ and $L W$, respectively) for the climatologies and their reliance on many years of sparse ship data over oceans. In the $S G$, the Pacific ITCZ is narrower from north to south, with higher peak values than in J. The SG exhib- its a broad local maximum in the eastern Pacific ITCZ, while $\mathrm{J}$ does not and $\mathrm{LW}$ exhibits higher values. An intercomparison of various satellite-derived precipi-
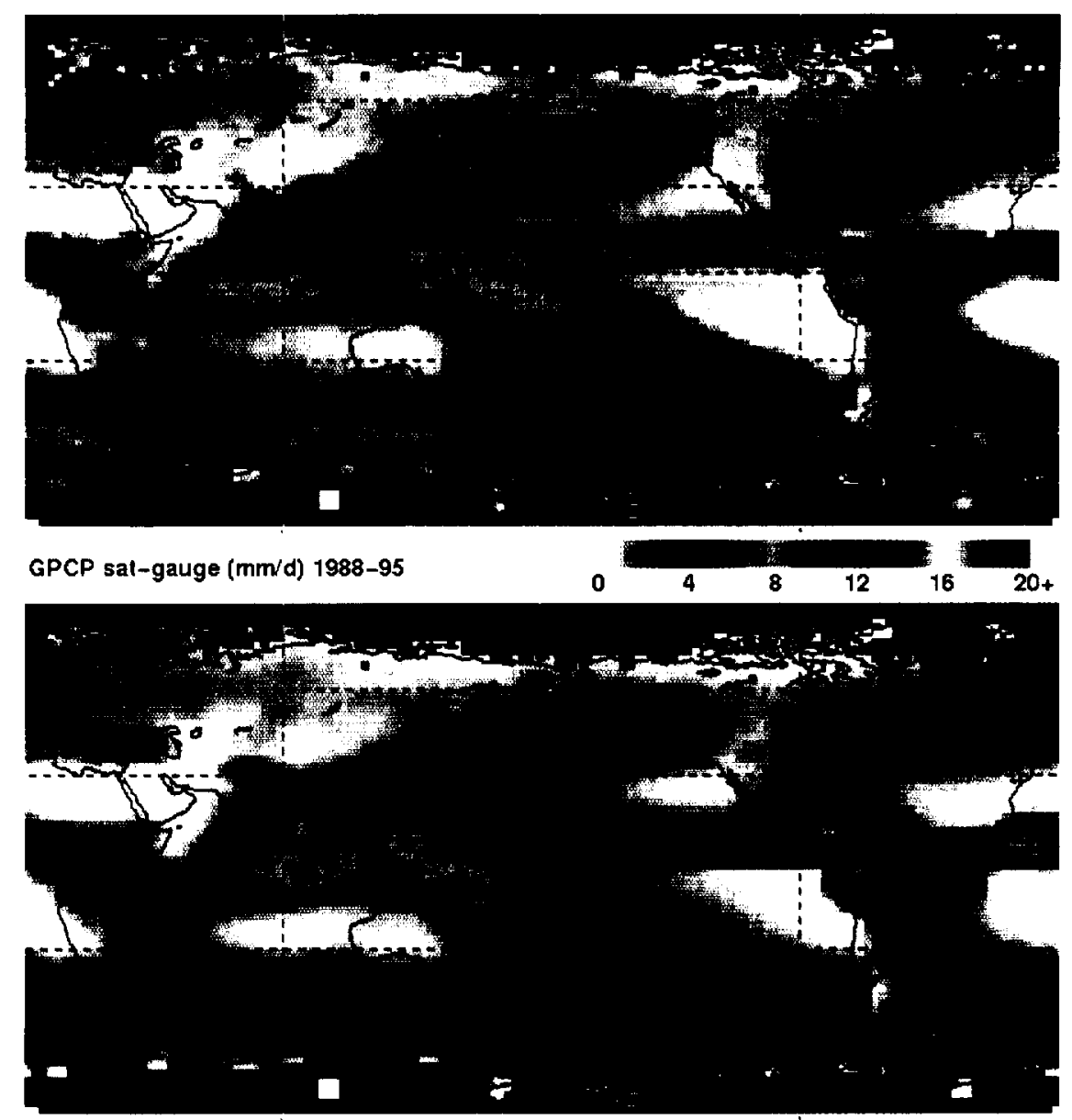

Matched Jaeger (mmid) 1988-95
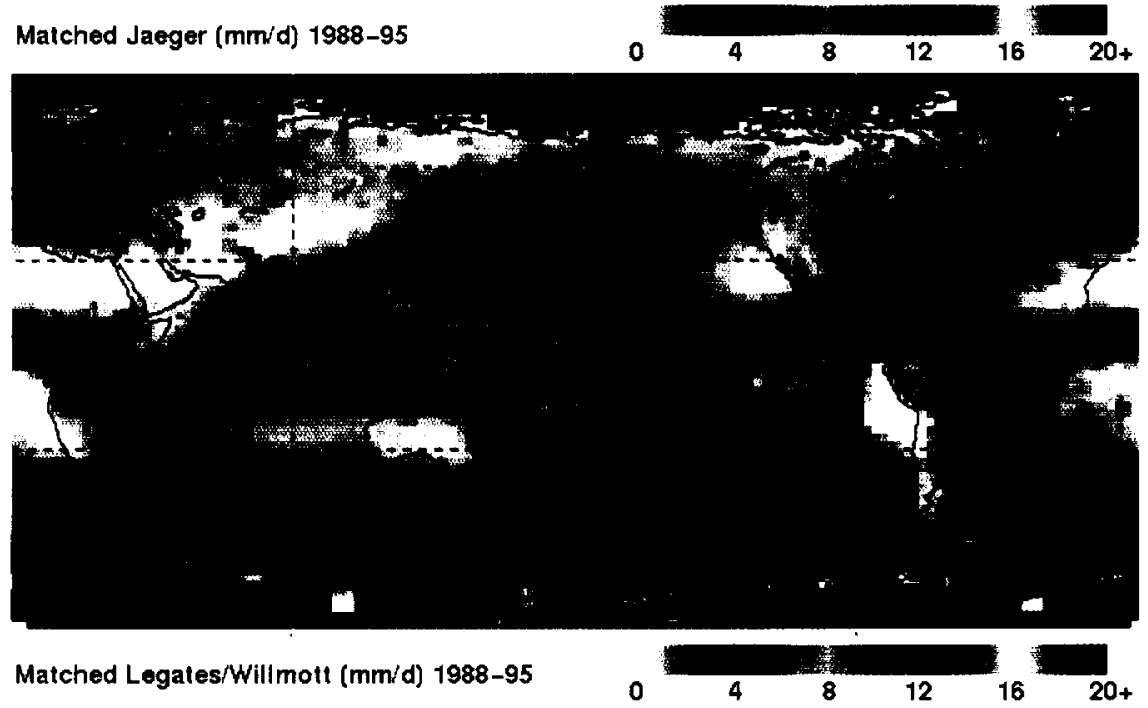

FIG. 3. Eight-year (1988-95) annual-mean precipitation in $\mathrm{mm} \mathrm{day}^{-1}$ for SG (top), Jaeger climatology ( $\mathrm{J}$; middle), and Legates-Willmott climatology (LW; bottom). For each grid box, the $\mathrm{J}$ and $\mathrm{LW}$ averages only have contributions for months that have SG data. Blackedout areas denote regions with no estimate. 

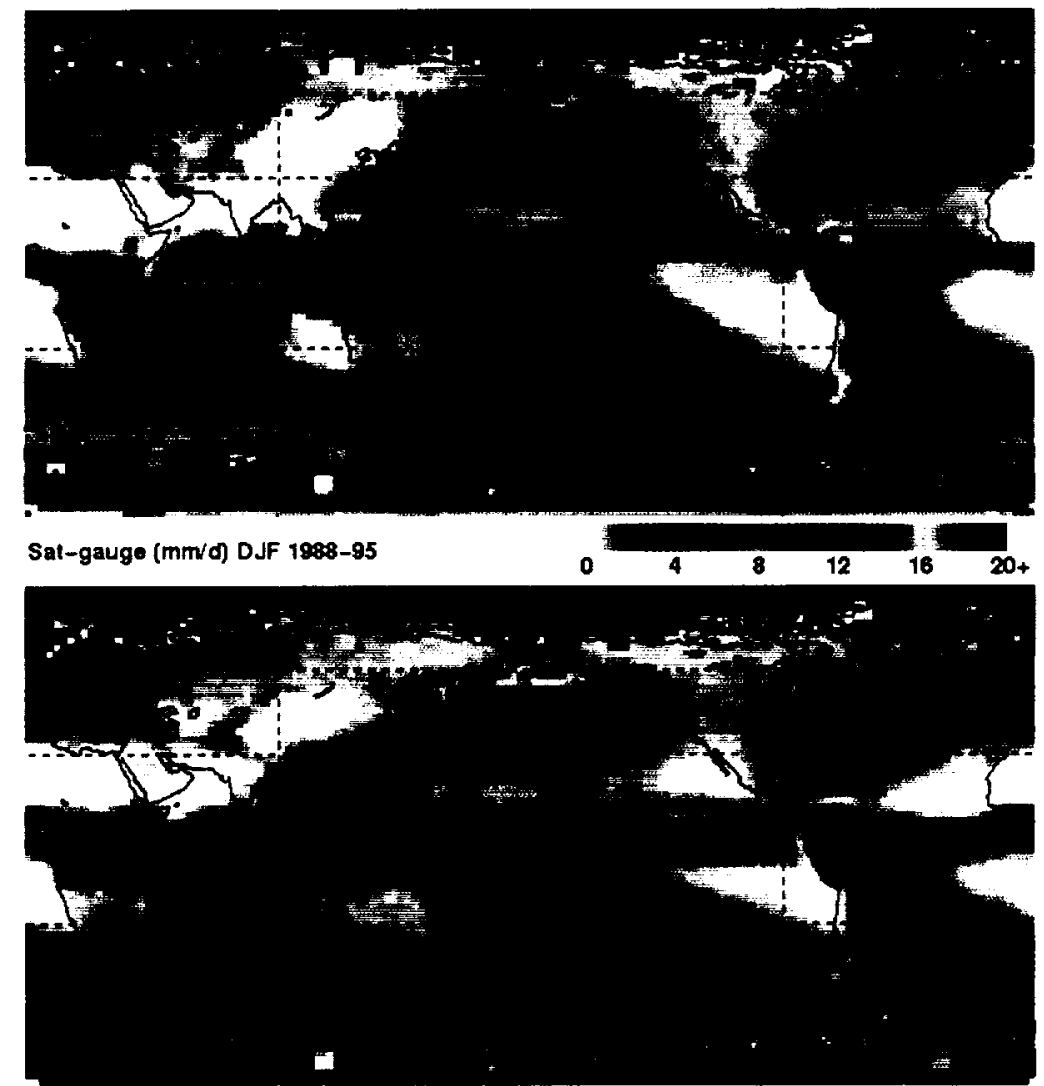

Sat-gauge (mm/d) MAM 1988-85
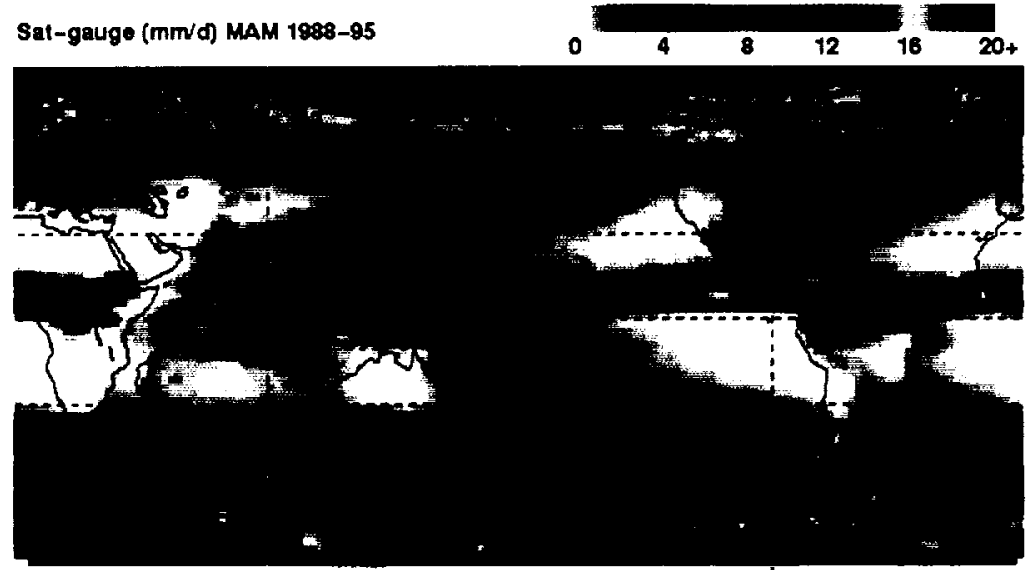

Sat-gauge (mm/d) JJA 1988-95
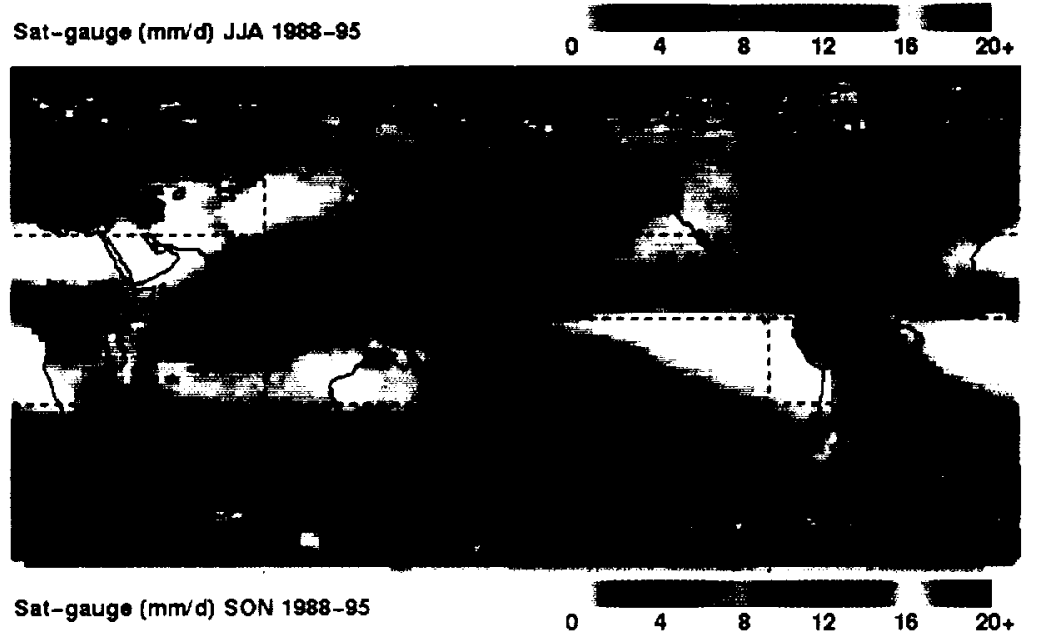

tation estimates by Janowiak et al. (1995) showed that there are large differences among the satellite-based estimates in this region, which appear to be related to frequent precipitation not associated with deep convection, and the satellite techniques' varying abilities to correctly estimate the precipitation under this condition. However, better validation data are required to establish the climatology in this area. West of the date line, the SG maximum in the ITCZ is more distinct than that in J but somewhat weaker than in LW. However, the differences are not as large as in the eastern Pacific. In the SPCZ, the maximum in the SG is weaker than in either climatology.

The Northern Hemisphere storm tracks in the SG are more intense than in either climatology. In J, peak amounts in the Pacific Ocean storm track are found in a broad maximum oriented parallel to the west coast of northern North America. In the SG, this is a more distinctly narrow coastal/orographic feature. Similarly, the broad maximum extending westward from southern South America in $\mathrm{J}$ is not evident in the SG. In LW, both these features are intermediate between the SG and J depictions. In the SG, the midlatitude storm track in the Southern Hemisphere exhibits local maxima to the south and east of Africa and South America that are not found in the climatologies.

\section{b. Eight-year seasonal means}

Maps of the 8-yr seasonal means based on the SG are shown in Fig. 4. The ITCZ in the Pacific and Atlantic Oceans is strongest in the June-August (JJA) and September-November (SON) periods with a very strong maximum in the eastem Pacific Ocean in JJA. The Pacific ITCZ is the weakest in December-February

Fig. 4. Eight-year (1988-95) seasonal-mean precipitation in $\mathrm{mm} \mathrm{day}^{-1}$ for SG. Blacked-out areas denote regions with no estimate. 
(DJF) and has a noticeable double structure in MarchMay (MAM), although the northern branch is still significantly stronger. The Southeast Asian monsoon is evident, with maximum intensity in JJA and oceanic rainfall maxima both east and west of India. The monsoon precipitation maximum shifts south- and eastward during SON, and reaches northern Australia in DJF. However, the intensity of the monsoon system is greatest by far during the Northern Hemisphere summer season. The SPCZ is evident throughout the year and is strongest in DJF. While its western boundary changes little through the year, it does expand to the north and east during DJF.

The North Pacific and North Atlantic storm tracks are present in all seasons but have their greatest eastward extent in SON and DJF. An axis of enhanced precipitation appears to connect the storm tracks to the low-latitude maxima over Central America and Southeast Asia in the warm seasons. In southern midlatitudes, the storm track is most clearly defined in JJA, with peak intensities in this season in the three oceanic maxima southeast of Africa, in the mid-Pacific, and southeast of South America.

Pronounced minima in precipitation are observed over the subtropical oceans and western subtropical continents in all seasons. The oceanic minima are strongest and most extensive during the summer seasons, while the continental minima exhibit movements that are related to the north-south seasonal migration of the tropical continental maxima.

The SG seasonal means exhibit good qualitative agreement with $\mathrm{J}$ over land but not over the oceans. Figure 5 shows the differences between JJA and DJF for both the SG and J. Over land, the patterns of seasonal change are remarkably consistent, with even minor features such as the DJF maximum over the U.S. Gulf Coast in agreement. Over the oceans, only the very largest scale fea- tures, such as the winter maximum in midlatitudes, agree and even those exhibit some inconsistencies, as in the western North Pacific. A substantial difference is seen in the eastern Pacific ITCZ, where the pronounced JJA maximum in the SG is not seen in $J$, which in fact shows a DJF maximum in part of this region.

\section{c. Full time series}

The time series of the global monthly precipitation rate based on the SG is shown in Fig. 6. To achieve globally complete fields, missing values in the SG monthly fields were filled with climatological precipitation values for the appropriate month and location according to J. The choice of fill-in is not critical as long as values are reasonable. For example, filling with forecast values produced by the operational European Centre for Medium-Range Weather Fore-
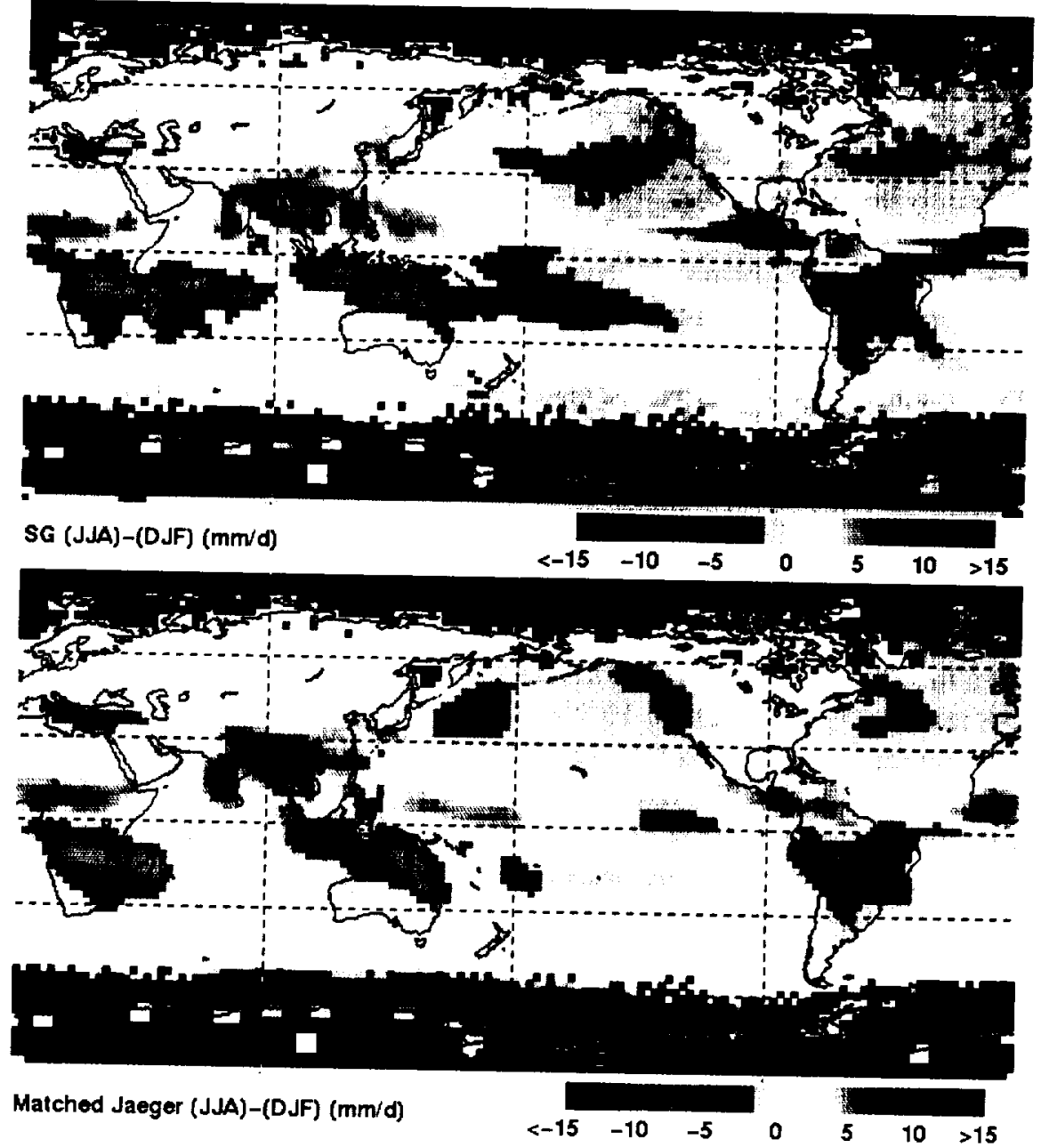

FIG. 5. Extreme-season (JJA-DJF) difference in $\mathrm{mm}^{-1 a y^{-1}}$ for $\mathrm{SG}$ (top) and $\mathbf{J}$ (bottom). For each grid box, the J average only have contributions for months that have SG data. Blacked-out areas denote regions with no estimate. 


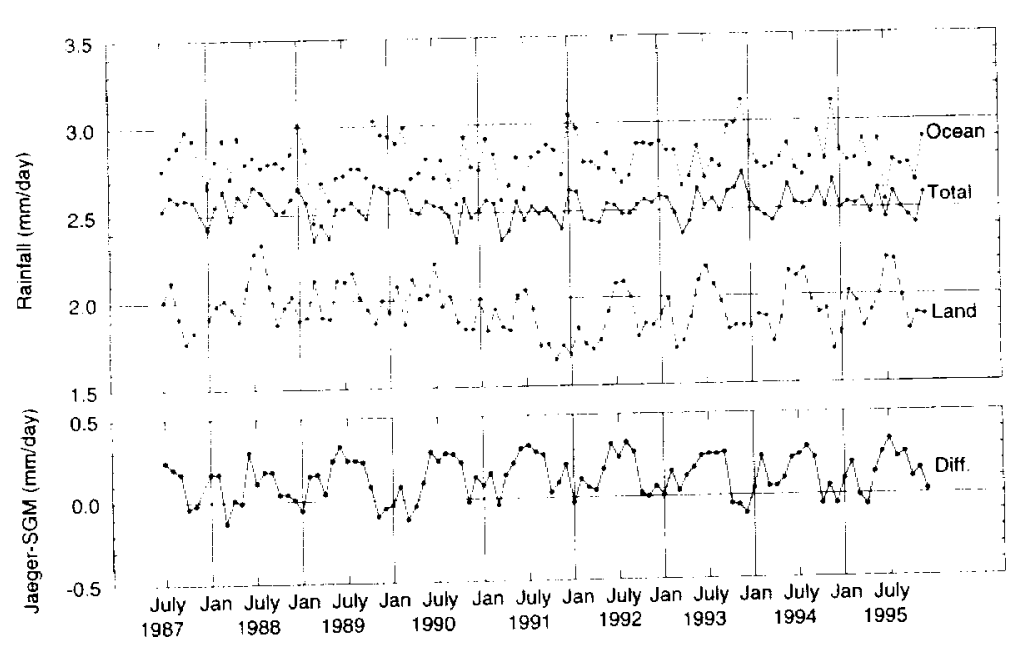

Fig. 6. Time series of the global monthly precipitation rate computed from the $\mathrm{SG}$ with holes in the field filled with corresponding J values (top), and (J - SGM) difference (bottom), both in $\mathrm{mm}^{-1} \mathrm{y}^{-1}$.
The subtropical dry zones (precipitation $<2 \mathrm{~mm} \mathrm{day}^{-1}$ ), centered near latitude $20^{\circ}$ in each hemisphere, are most intense (driest) during the winter season. During late summer in each hemisphere when the migrating tropical maximum is near its poleward extreme, a band of heavier precipitation extends to midlatitudes. A band of heavier amounts is found centered near latitude $40^{\circ}$ in each hemisphere throughout the year. In the Northern Hemisphere, extensions of this heavy band to higher latitudes are seen in late summer and fall, but annual and interannual variability in intensity is small. In the Southern Hemisphere, no such extension to higher latitudes is visible. However, a modest annual cycle, with maximum values exceeding $4 \mathrm{~mm} \mathrm{day}^{-1}$ in midwinter, and some interannual variability can be seen.

casts numerical weather prediction system yield values that differ by no more than $0.2 \mathrm{~mm} \mathrm{day}^{-1}$ for any one month and average $0.06 \mathrm{~mm}^{-1} \mathrm{day}^{-1}$ higher for the 8 -yr average. The average global total precipitation for the 8 -yr period is $2.53 \mathrm{~mm}^{\text {day }}{ }^{-1}$ with a substantially higher value over water than over land. The difference between the SG and J global means (Fig. 6, bottom) is nearly always positive (GPCP less) with an average of about $0.3 \mathrm{~mm}^{-1 a y^{-1}}$. Over land the seasonal cycle is very evident, with a maximum in the boreal summer presumably associated with the maximum in Southeast Asian monsoon precipitation during that season.

The zonally averaged precipitation in the belt $60^{\circ} \mathrm{N}-\mathrm{S}$ during the $8.5 \mathrm{yr}$ (Fig. 7 ) exhibits a pronounced annual cycle in the Tropics and subtropics

\section{d. ENSO signal}

One of the most important prospective uses of any analysis of global precipitation is to examine and understand interannual changes in the distribution of large-scale precipitation and their relationship to variations in the general circulation. It has long been clear that a significant portion of the interannual variability in the large-scale atmospheric circulation is associated with the ENSO phenomenon (Bjerknes 1969; Arkin 1982). ENSO-related changes in global precipitation as inferred from rain gauge observations have been presented by Ropelewski and Halpert (1987, 1989, 1996), and Janowiak and Arkin (1991) and but only modest interannual variability. Heaviest precipitation (zonal averages $>8 \mathrm{~mm} \mathrm{day}^{-1}$ ) is found near $10^{\circ} \mathrm{N}$ in the late boreal summer. This feature is part of a belt of maxima that reaches its farthest northward extent about September and extends farthest southward, past $15^{\circ} \mathrm{S}$, in March. Rasmusson and Arkin (1993) described this pattern using only IR-based estimates (their Fig. 20), finding the latitudinal extrema in August and February. The apparent continuity between the summer maxima in each hemisphere in Fig. 7 was not found by Rasmusson and Arkin except during the 1986-87 warm episode.

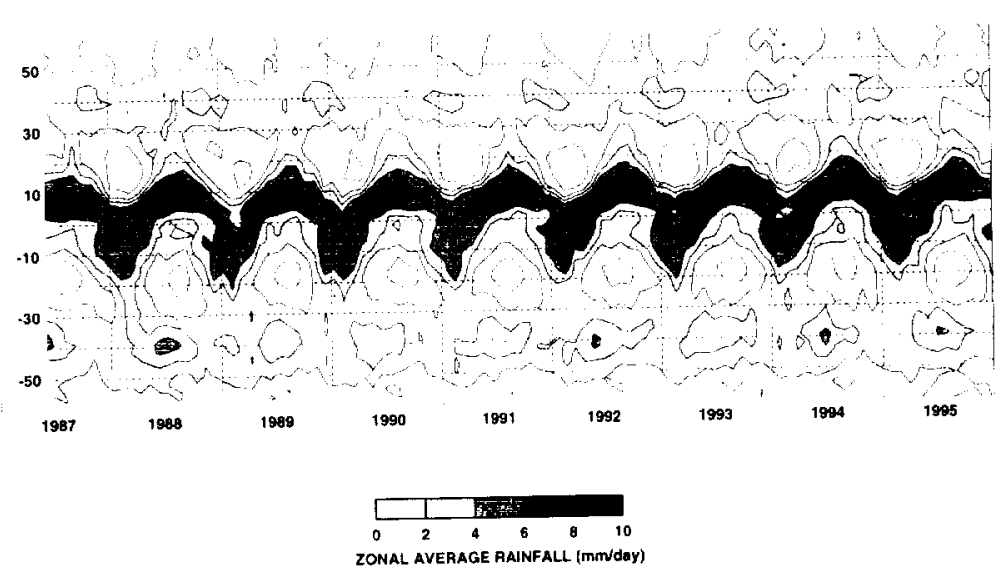

Fig. 7. Time series of the zonal-average SG precipitation in $\mathrm{mm} \mathrm{day}^{-1}$ over the belt $60^{\circ} \mathrm{N}-\mathrm{S}$. 
Arkin et al. (1994) have described the ENSO signal in precipitation estimated from satellite observations. In this section, we will describe the precipitation changes associated with changes in the state of ENSO during the period of analysis and compare them to those that occurred during previous episodes.

The period covered by the GPCP analysis was characterized by a warm episode that began in late 1986, a cold episode during 1988-89, and a warm episode during 1991-93 (Arkin et al. 1994; Kousky 1987). The latter was most pronounced during the DJF seasons of 1991/92 and 1992/93, and less clear during the JJA seasons (Kousky 1993; Mo and Wang 1994).

The top panel of Fig. 8 shows the difference in precipitation between a warm episode DJF (1991/92) and a cold episode DJF (1988/89). Large differences are found across the equatorial Pacific Ocean, extending into the midlatitudes of the southern Pacific and across the Maritime Continent into the Indian Ocean. Amounts are greater during the warm episode in the Central Pacific and the east Pacific ITCZ, and less farther west. The SPCZ appears to be displaced toward the north and east during the warm episode. Coherent-appearing features of lesser amplitude can be seen elsewhere: greater amounts during the warm episode in the subtropical southern Indian Ocean, at the North American terminus of the North Pacific storm track, over the U.S. Gulf Coast, and over portions of Argentina and Uruguay; and lesser amounts during the warm episode over southern Africa and the adjacent Indian Ocean, the central North Pacific, and equatorial South America and the adjacent Atlantic Ocean.

Differences between warm and cold episodes during the JJA season are slightly more difficult to describe. The JJA season of 1992, while nominally part of an extended warm episode, actually was characterized by near-normal sea surface temperatures in the equatorial Pacific, with some below-normal values in the region of the climatological cold tongue (Mo and Wang 1994). The JJA season of 1987 was more representative of canonical warm episode conditions (Janowiak and Arkin 1991), but the GPCP Version 1 analysis is not available during the first part of that season. We will use both JulySeptember (JAS) 1987 and JJA 1992 as examples of warm ENSO conditions during the boreal summer, while JAS 1988 and JJA 1988 will serve as the corresponding cold episode examples. The difference map for JAS 1987-JAS 1988 (bottom panel of Fig. 8) exhibits a band of heavier (lighter) precipitation during the warm (cold) episode extending the entire width of the tropical Pacific Ocean and into Southeast Asia to near $90^{\circ} \mathrm{E}$. In the eastern Pacific, this band appears to represent an enhanced and southward-displaced ITCZ, with some differences of opposite sign along its northern boundary. From $150^{\circ} \mathrm{W}$ to $140^{\circ} \mathrm{E}$,
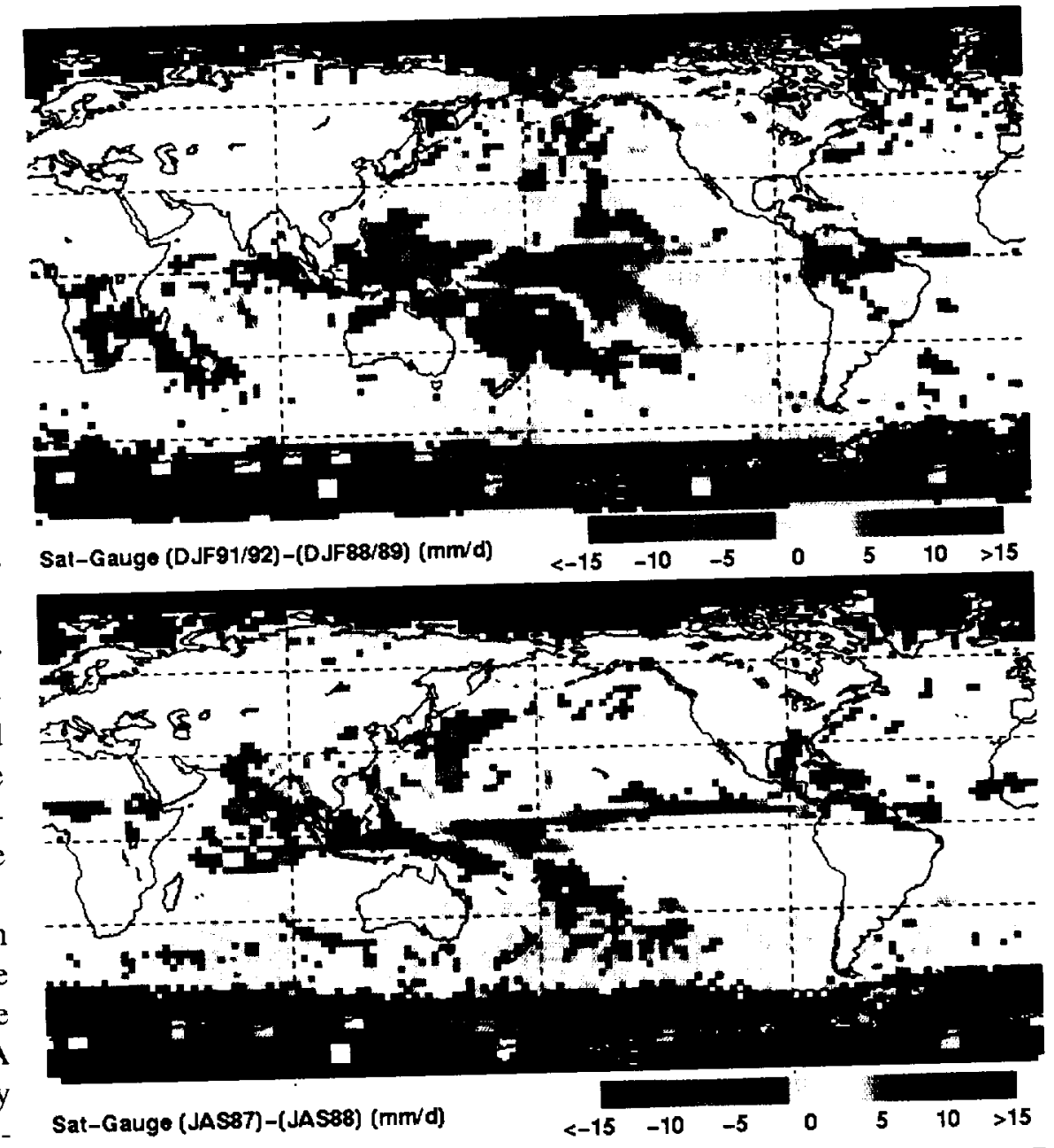

FIG. 8. (El Niño-La Niña) differences in mm day ${ }^{-1}$ computed from SG fields for (DJF 1991/92-DJF 1988/89) (top) and (JAS 1987-JAS 1988) (bottom).

Bulletin of the American Meteorological Society 
program (Daly et al. 1994). PRISM is based on linear regressions of gauge precipitation and terrain (slope and elevation). The regression equations are used with a very fine grid of elevations and slopes (obtained from a digital elevation model) to infer precipitation over the entire grid.

Although both SRDC and GPCC provide gauge analyses, the datasets are quite different. The SRDC analyses are based on more gauges than the GPCC analyses (Table 1).

As well, the analysis techniques take different approaches. Very few of the GPCC and SRDC gauges are collocated, and the SRDC analyses do not change significantly when GPCC sites are excluded from SRDC analyses. Except for these few cases, the GPCC and SRDC analyses are independent in the sense that they are not based on data from the same gauges. In a deeper sense the two analyses cannot be independent since correlation distances for monthly averages exceed the typical interstation spacing in the SRDC dataset.

Two error measures are available for the SRDC analysis. The first is a confidence interval that represents the fit of the gauge data to the linear functions used to interpolate precipitation. This conservative estimate of the uncertainty in the relation between precipitation and elevation is most applicable in mountainous areas. The average of the $70 \%$ prediction confidence interval is $\pm 0.95 \mathrm{~mm}$ day $^{-1}$. The second error measure is the cross-validation error, the average difference between an observed gauge value and the regression-estimated value at the gauge location. The cross-validation error ranges from -0.92 to $0.36 \mathrm{~mm}$ day $^{-1}$ in the SRDC dataset, with an average of $-0.03 \mathrm{~mm} \mathrm{day}^{-1}$.

The SRDC analysis was compared to the GPCP Version $1 \mathrm{MS}$, gauge, and SG analyses, producing the summary statistics in Table 2. Scatterplots for the individual matchups are displayed in Fig. 10. As expected, the MS field (which is the AGPI estimate for all SRDC test sites, except Canada) shows a relatively large root-mean-square (rms) error. The gauge is somewhat surprisingly close to the SRDC despite the small number of gauges. This correlation between the two gauge-based datasets is not due to duplicate gauge data, which occur only occasionally; it indicates the importance of a good analysis system. Although well correlated, the gauge analysis has a positive bias, which is improved in the SG.

Figure 10 shows fewer large errors for the SG than for the gauge but slightly more spread close to the 1:1 line. Quantitatively, this is reflected in lower rms error for the SG but higher average absolute error (Table 2). One constraint on improvement is that the satellite values are adjusted to the large-scale gauge bias before combination. This step works as intended in pulling the SG bias toward the gauge bias, but it has the side effect of smearing steep gradients. It should also be noted that the SRDC validation results show seasonal and regional variations, so that the average results shown here depend on the locations and sizes of test sites. Thus, we are of the opinion that the performance of the SG combination is acceptable, even with the current strong approximations in estimating error.

On the whole, the estimated rms errors track with the SRDC-based rms errors (i.e., differences from SRDC) for the various fields as a function of rain total. However, the estimates tend to be lower than the actual for all but the gauge, which was calibrated from the SRDC. We interpret this result as indicating that the SRDC test sites have higher variability in the satellite fields than the average for all of the land areas in the zone $40^{\circ} \mathrm{N}-\mathrm{S}$ (which were used to develop the coefficients). About half of the test sites are in coastal areas, which we often observe to have higher variability in precipitation than continental interiors or open

\section{Concluding remarks}

The GPCP has released a new set of global precipitation estimates based on the sequential combination 

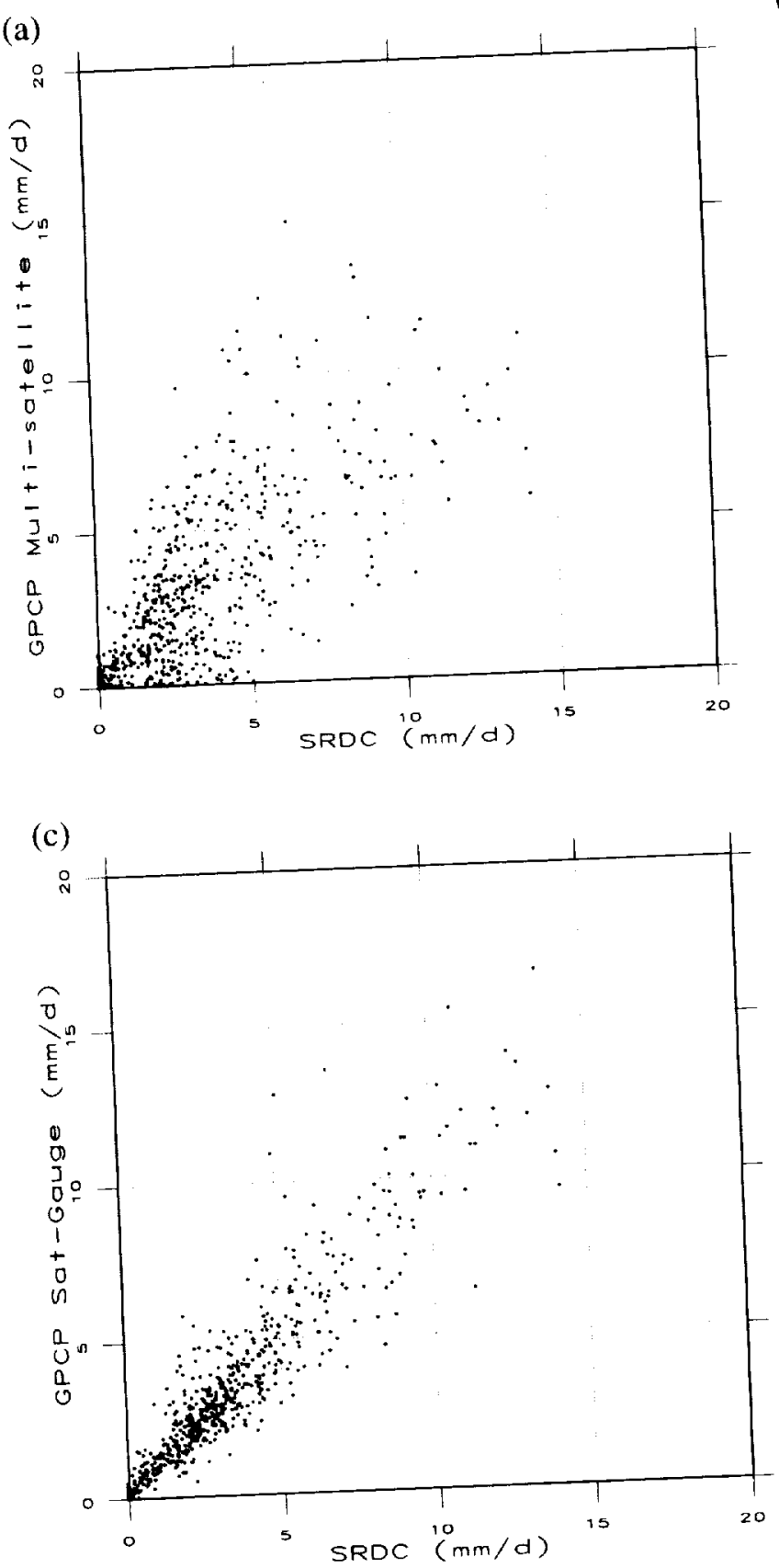

of microwave, IR, and gauge data. At each stage, biases were removed where possible, and the combination is tailored to the types of data. The dataset covers the period July 1987 through December 1995 on a monthly $2.5^{\circ} \times 2.5^{\circ}$ lat-long grid. Each input and combination field is a separate product, and estimates of the random part of the error are provided with each precipitation field. These (spatially and temporally varying) errors allow users to assess the utility of the grid values for their own application. Such applications might include validation of numerical climato-

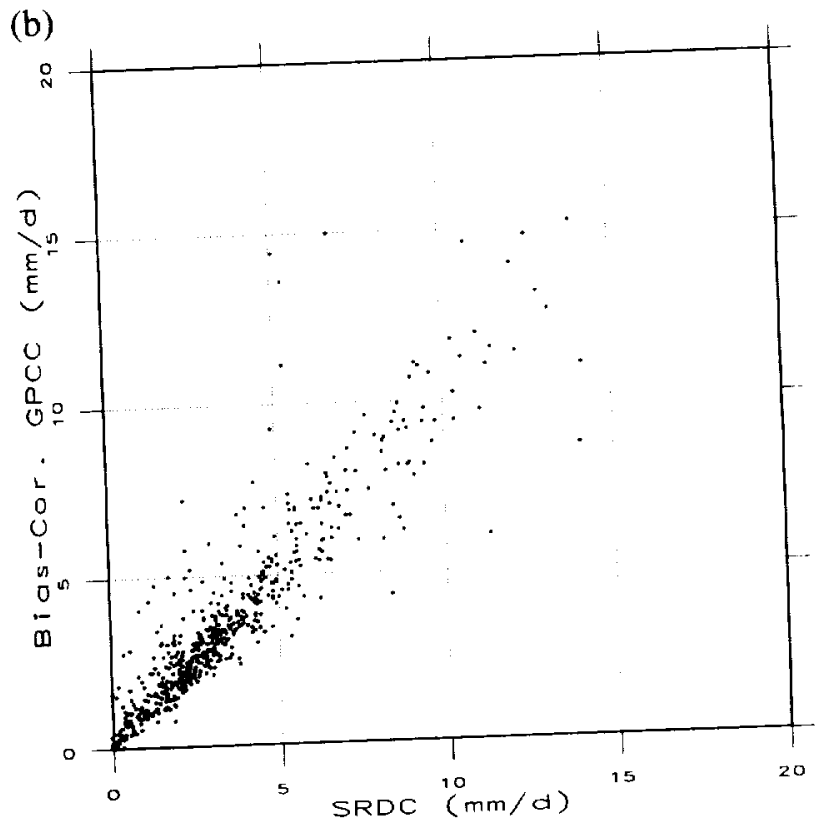

FIG. 10. Scatterplots of (a) MS, (b) gauge, and (c) SG versus SRDC, all in $\mathrm{mm}$ day $^{-1}$ for all cells and months.

logical models, calibration of hydrological models, and benchmarking of experimental rainfall estimation techniques.

Time- and space-averaged Version 1 combined satellite-gauge fields show fair agreement with standard climatologies, for example yielding a global annual-average precipitation rate of $2.5 \mathrm{~mm}^{\text {day }}{ }^{-1}$, which corresponds remarkably well to previous climatological estimates. On seasonal and regional scales systematic differences start to appear. Validation over land shows that the Version 1 multisatellite combination provides useful information, but the addition of even a few gauges greatly improves the estimate.

Four major themes are likely for future releases of the GPCP combination. Extension to earlier periods that lack SSM/I data is needed to fulfill the mandate to start in 1986. Error estimation needs to be improved and refined. A whole class of users would benefit from globally complete fields. A research version of globally complete fields is already in development, based on the use of estimates of precipitation from four-dimensional data assimilation models. Finally, upcoming satellites such as Tropical Rainfall Measurement Mission hold great promise for refining the calibrations of the SSM/I and GPCP estimates.

The GPCP Version 1 Combined Precipitation Data Set is archived at World Data Center A (WDC-A; 
Asheville, North Carolina), which is collocated with NCDC. The most current release is Version 1a. Datasets may be obtained by contacting A. McNab (704-2714592; NCDC, Federal Buildling, 151 Patton Ave., Asheville, NC 28801-5001), by Internet access to the WDC-A home page (URL http://www.ncdc.noaa.gov/ wdcamet.html\#GPCP), or by anonymous FTP. For the last, FTP to ftp.ncdc.noaa.gov, $\log$ in as "anonymous" using your complete e-mail address as the password, "cd" to subdirectory pub/data/gpcp/version 1, set binary transfer mode, and "get" the file readme.txt. Files are binary, providing 1 yr of data for a particular data field (a variable from a technique).

Acknowledgments. The GPCP Version 1 Combined Precipitation Data Set is produced under the auspices of the GPCP Working Group on Data Management. P. Xie and R. Joyce (Research and Data Corp.; NOAA/NCEP) contributed to dataset preparation. P. Keehn (Science Systems and Applications, Inc.; NASA/GSFC Laboratory for Atmospheres) assisted with dataset generation, management, and visualization. Some of the geostationary satellite data were prepared by the Japan Meteorological Agency, the European Space Agency, and EUMETSAT. Ongoing support for the activities described in this paper by Deutscher Wetterdienst, National Aeronautics and Space Administration, and National Oceanic and Atmospheric Administration is gratefully acknowledged.

\section{References}

Adler, R. F., A. J. Negri, P. R. Keehn, and I. M. Hakkarinen, 1993: Estimation of monthly rainfall over Japan and surrounding waters from a combination of low-orbit microwave and geosynchronous IR data. J. Appl. Meteor., 32, 335-356.

- , G. J. Huffman, and P. R. Keehn, 1994: Global rain estimates from microwave-adjusted geosynchronous IR data. Remote Sens. Rev., 11, 125-152.

Arkin, P. A., 1982: The relationship between interannual variability in the $200 \mathrm{mb}$ tropical wind field and the Southern Oscillation. Mon. Wea. Rev., 110, 1393-1404.

- - , and B. N. Meisner, 1987: The relationship between large-scale convective rainfall and cold cloud over the Western Hemisphere during 1982-1984. Mon. Wea. Rev., 115, 51-74.

- and P. Xie, 1994: The Global Precipitation Climatology Project: First Algorithm Intercomparison Project. Bull. Amer. Meteor. Soc., 75, 401-419.

- , R. Joyce, and J. E. Janowiak, 1994: IR techniques: GOES Precipitation Index. Remote Sens. Rev., 11, 107-124.

Bjerknes, J., 1969: Atmospheric teleconnections from the equatorial Pacific. Mon. Wea. Rev., 97, 163-172.

Chang, A. T., L. S. Chiu, and G. Yang, 1995: Diurnal cycle of oceanic precipitation from SSM/I data. Mon. Wea. Rev., 123, 3371-3380.

Chiu, L., A. Chang, and J.E. Janowiak, 1993: Comparison of monthly rain rates derived from GPI and SSM/I using probability distribution functions. J. Appl. Meteor., 32, 323-334.
Daly, C., R. P. Neilson, and D. L. Phillips, 1994: A statisticaltopographic model for mapping climatological precipitation over mountainous terrain. J. Appl Meteor., 33, 140-158.

Ferraro, R. R, and G. F. Marks, 1995: The development of SSM/I rain-rate retrieval algorithms using ground-based radar measurements. J. Atmos. Oceanic Technol., 12, 755-770.

$\longrightarrow$, N. C. Grody, and G. F. Marks, 1994: Effects of surface conditions on rain identification using the SSM/I. Remote Sens. Rev., 11, 195-209.

Grody, N. C., 1991: Classification of snow cover and precipitation using the Special Sensor Microwave/Imager (SSM/I). J. Geophys. Rev., 96, 7423-7435.

Huffman, G. J., R. F. Adler, B. Rudolf, U. Schneider, and P. R. Keehn, 1995: Global precipitation estimates based on a technique for combining satellite-based estimates, rain gauge analysis, and NWP model precipitation information. J. Climate, 8, 1284-1295.

Jaeger, L., 1976: Monatskarten des Niedershlags für die ganze Erde. Ber. Dtsch. Wetterdienstes, 139, 33 pp. plus plates

Janowiak, J. E., and P. A. Arkin, 1991: Rainfall variations in the tropics during 1986-1989. J. Geophys. Res., 96, 3359-3373.

,,-- P. Xie, M. L. Morrissey, and D. R. Legates, 1995: An examination of the east Pacific ITCZ rainfall distribution. J. Climate, 8, 2810-2823.

Kousky, V. E., 1987: The global climate for December 1986 February 1987: El Niño returns to the tropical Pacific. Mon. Wea. Rev., 115, 2822-2838.

- 1993: The global climate for December 1991-February 1992: Mature-phase warm (ENSO) episode conditions develop. J. Climate, 6, 1639-1655.

Legates, D. R., 1987: A Cimatology of Global Precipitation. Publications in Climatology, Vol. 40, University of Delaware, 85 pp.

- , and C. J. Willmott, 1990: Mean seasonal and spatial variability in gauge-corrected, global precipitation. Int. J. Climatol., 10, 111-127.

Mo, K. C., and X. Wang, 1994: The global climate of JuneAugust 1992: Warm ENSO episode decays and colder than normal conditions dominate the Northern Hemisphere. J. Climate, 7, 335-357.

Morrissey, M. L., and J. S. Green, 1991: The Pacific Atoll Raingauge Data Set. Planetary Geosci. Div. Contrib. 648, University of Hawaii, 45 pp.

North, G. R., S. S. P. Shen, and R. B. Upson, 1991: Combining rain gages with satellite measurements for optimal estimates of area-time averaged rain rates. Water Resour. Res., 27, 2785-2790.

Rasmusson, E. M., and T. H. Carpenter, 1982: Variations in tropical sea surface temperature and surface wind fields associated with the Southern Oscillation/El Niño. Mon. Wea. Rev., 110, 354-384.

cipitation variability. J. Climate, 6, 1495-1522.

Ropelwski, C. F., and M. S. Halpert, 1987: Global and regional scale precipitation patterns associated with the El Niño/Southern Oscillation. Mon. Wea. Rev., 115, 1606-1626.

- and -1989 : Precipitation patterns associated with the high index phase of the Southern Oscillation. J. Climate, 2, 268-284.

_- and _- 1996: Quantifying Southern Oscillation-precipitation relationships. J. Climate, 9, 1043-1059. 
Rudolf, B., 1993: Management and analysis of precipitation data on a routine basis. Proc. Int. WMO/LAHS/ETH Symp. on Precipitation and Evaporation, Bratislava, Slovakia, Slovak Hydromet. Inst., 69-76.

_, H. Hauschild, W. Rüth, and U. Schneider, 1996: Comparison of raingauge analyses, satellite-based precipitation estimates, and forecast model results. Adv. Space Res., 18, 5362.

Schneider, U., 1993: The GPCC quality-control system for gaugemeasured precipitation data. Report of the GEWEX workshop Analysis Methods of Precipitation on a Global Scale, Koblenz, Germany, WMO/TD-No. 558, A5-A7. [Available from World Meteorological Organization, P.O. Box 2300, CH-1211 Geneva 2, Switzerland.]

_, and H. E. Fleer, 1989: Development of sea surface temperature, surface wind and divergence anomalies during a composite ENSO episode. Theor. Appl. Climatol., 39, 146-159.

, and B. Rudolf, 1994: Differences between 1987 and 1988 summer monsoon rainfall over India, Southeast Asian and the northern Indian Ocean as obtained from the preliminary GPCP merged global data set. Proc. Int. Conf. on Monsoon Variability and Prediction, Trieste, Italy, World Meteor. Org., 245-252.
Sevruk, B., 1989: Reliability of precipitation measurements. Proc. WMO/IAHS/ETH Workshop on Precipitation Measurements, St. Moritz, Switzerland, World Meteor. Org., 13-19.

Weng, F., and N. C. Grody, 1994: Retrieval of cloud liquid water using the Special Sensor Microwave Imager (SSM/I). J. Geophys. Res., 99, 25 535-25 551.

_- R. Ferraro, and N. Grody, 1994: Global precipitation evaluation using Defense Meteorological Satellite Program F10 and F1 1 Special Sensor Microwave Imager data. J. Geophys. Res., 99, 14 493-14 502.

Wilheit, T., A. Chang, and L. Chiu, 1991: Retrieval of monthly rainfall indices from microwave radiometric measurements using probability distribution function. J. Atmos. Oceanic Technol., 8, 118-136.

Wilmott, C. J., C. M. Rowe, and W. D. Philpot, 1985: Small-scale climate maps: A sensitivity analysis of some common assumptions associated with grid-point interpolation and contouring. Amer, Cartographer, 12, 5-16.

WCRP, 1986: Report of the workshop on global large scale precipitation data sets for the World Climate Research Programme, WCP-111, WMO/TD-No. 94, 45 pp. [Available from World Meteorological Organization, P.O. Box 2300, CH1211 Geneva 2, Switzerland.]

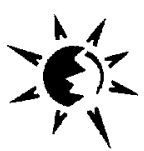

